\title{
Continual conscious bioluminescent imaging in freely
}

\section{moving mice}

Running head title - Whole-body bioluminescent imaging of freely moving mice

Juan Antinao Diaz, ${ }^{1}$ Amy Geard ${ }^{2,3}$, Lorna M. FitzPatrick, ${ }^{4}$ Juliette M.K.M Delhove5, Suzanne

M.K. Buckley ${ }^{1}$, Simon N. Waddington ${ }^{1,3}$, Tristan R. McKay ${ }^{4}$, \& Rajvinder Karda ${ }^{1}$

1. Gene Transfer Technology Group, Institute for Women's Health, University College London, UK

2. UCL School of Pharmacy, University College London, UK

3. Wits/SAMRC Antiviral Gene Therapy Research Unit, Faculty of Health Sciences, University of the Witwatersrand, Johannesburg, South Africa.

4. Centre for Biomedicine, Manchester Metropolitan University, Manchester, UK

5. Robinson Research Institute, University of Adelaide, Adelaide, Australia

${ }^{*}$ Correspondence should be addressed to R.K (r.karda@ucl.ac.uk) 


\begin{abstract}
In vivo bioluminescent imaging allows the detection of reporter gene expression in rodents in real time. Here we describe a novel technology whereby we can generate somatotransgenic rodents with the use of a viral vector carrying a luciferase transgene. We are able to achieve long term luciferase expression by a single injection of lentiviral or adeno-associated virus vectors to new-born mice. Further, we describe whole body bioluminescence imaging of conscious mice in a non-invasive manner, thus enforcing the $3 R^{\prime}$ s (replacement, reduction, and refinement) of biomedical animal research.
\end{abstract}

Key words: Lentiviral vectors, Adeno-associated vectors, Transcription factor activated reporter, Biosensors, Luciferase, Neonatal mice, Luciferin, Bioluminescence imaging, Conscious imaging

\title{
1 Introduction
}

Bioluminescence imaging has been established for many years with the use of germline transgenics. In germline light producing transgenic (LPT) models the luciferase transgene is inserted downstream of an endogenous gene promoter and thus results in every cell carrying a copy of the luciferase reporter gene [1], [2]. The advantage of this technology is that it provides a whole-body readout of the specific promoter or enhancer activity.

However, monitoring bioluminescence from individual organs and tissues has proven to be difficult due to the "background noise" generated by the whole-body bioluminescence.

Furthermore, LPTs are produced by frequent backcrossing, which results in increased time, cost and number of animals. 
We have developed a novel technology whereby we can deliver a luciferase reporter gene using viral vectors (lentivirus and adeno-associated virus (AAV)), directly to the targeted tissue of new-born rodents, to generate somatotransgenic animals. We have previously shown that viral vector delivery to neonatal mice confers immune tolerization to the transgenic protein [3] and long-term gene expression [4]. Viral vectors can be engineered for cell or tissue specificity by pseudotyping or by capsid engineering, with specific viral envelopes or capsids. The development of highly sensitive charge coupled device (CCD) cameras has allowed the continual detection of luciferase activity in a non-invasive manner on live mice [5].

Previous studies have shown that prolonged exposure to isoflurane can cause primary neuronal axon outgrowth [6], microglia activation, cell death and disruption of neurodevelopment [7]. We therefore interrogated the use of somatotransgenic bioimaging technology as a means of quantifying bioluminescent imaging on conscious moving mice [8]. Using a mouse model of cerebral palsy, we monitored inflammation in a non-invasive manner, and established that there was no difference in luciferase expression between conscious and unconscious mice. This demonstrates the utility of the methodology and is conducive to implementation of the 3R's of biomedical animal research to replace or reduce animal numbers or refine methods involving their use [8].

\section{Materials}

\subsection{Plasmids}

Both lentiviral and AAV biosensor plasmids were designed to be compatible with Gateway ${ }^{\circledR}$ cloning technology. The plasmids contain a Gateway ${ }^{\circledR}$ recombination cassette, 
upstream of a 3x FLAG-tagged tag, codon-optimised luciferase reporter gene, linked by a T2A bicistronic linker and an enhanced green fluorescent protein (GFP), referred to as pLNT-GW-JDG and AAV-GW-JDG (Fig. 1) [1], [9]. Entry plasmids were also designed, which contained the promoter or transcription factor response element of choice [10] (Fig. 1). Plasmids should always be dissolved in sterile TE buffer or in nuclease free water.

1. Lentiviral plasmid pLNT-GW-JDG.

2. AAV plasmid AAV-GW-JDG (synthesised from Aldevron).

3. Entry plasmid pENTR (Aldevron) containing response element of choice.

[Figure 1 near here]

2.2 Cloning

1. LR Clonase kit (Invitrogen)

2. DH5 $\alpha$ chemically competent cells.

3. Stbl3 or NEB Stable chemically competent cells.

4. BamHI and EcoRI restriction enzymes.

5. Appropriate restriction enzyme that can be used to screen clones.

6. LB broth: $5 \mathrm{~g} / \mathrm{l}$ yeast extract, $5 \mathrm{~g} / \mathrm{l} \mathrm{NaCl}, 10 \mathrm{~g} / \mathrm{l}$ peptone, $5 \mathrm{mM} \mathrm{NaOH}$.

7. LB agar: LB medium containing $14 \mathrm{~g} / \mathrm{l}$ agar.

2.3 Lentiviral production: Plasmids

Plasmids should always be dissolved in sterile TE buffer or in nuclease free water.

1. Envelope plasmid VSV-G (pMD2.G). 
2. Packaging plasmid gag-pol, tat, rev plasmid (pCMV $\Delta$ R8.74).

3. Payload plasmid pLNT-Response element-JDG.

2.4 Lentiviral production: Cell culture and transfection

1. HEK293T cells (Biobank at Institute of Child Health, University College London).

2. $37^{\circ} \mathrm{C}$ cell culture incubator with $5 \% \mathrm{CO}_{2}$ atmosphere.

3. DMEM supplemented with $10 \%$ fetal bovine serum and $1 \%$ Pen/Strep.

4. Tissue culture flasks, T175.

5. Opti-MEM.

6. Trypsin-EDTA.

7. Phosphate buffered saline (PBS).

8. $\quad 0.45 \mu \mathrm{m}$ PVDF membrane filters.

9. Polyethylenimine (PEI) Max MW 40,000 (Polysciences Inc).

2.5 AAV production: Plasmids

Plasmids should always be dissolved in sterile TE buffer or in nuclease free water.

1. Helper plasmid pHGTI.

2. Packaging plasmid, in this chapter pAAV2/8.

3. Payload plasmid AAV-Response element-JDG.

2.6 AAV production: Cell culture and transfections

1. AAV pro 293T cells (Takara Bio). 
2. $37^{\circ} \mathrm{C}$ cell culture incubator with $5 \% \mathrm{CO}_{2}$ atmosphere.

3. DMEM supplemented with $10 \%$ fetal bovine serum and $1 \%$ Pen/Strep.

4. $15 \mathrm{~cm}$ Tissue culture dishes.

5. Opti-MEM.

6. Cell scrappers.

7. $\quad 0.22 \mu \mathrm{m}$ and $0.45 \mu \mathrm{m}$ PVDF membrane filters.

8. PEI MW 40,000.

9. $0.1 \%$ PEI solution: $1 \mathrm{~g}$ of PEI MW 40,000, $900 \mathrm{~mL}$ of $\mathrm{dH}_{2} \mathrm{O}, \mathrm{pH}$ to 7.2 , make up to $1 \mathrm{~L}$

10. TD Buffer: 140 mM NaCl (MW 58.44; 8.181 g/L), 5 mM KCl (MW 74.56; 372.8 mg/L), 0.7 mM K2 $\mathrm{HPO}_{4}$ (MW 174,18; 121.9 mg/L), 3.5 mM MgCl (MW 95.21; 333.23 mg/L), 25 mM Tris (MW 121.14; $3.0285 \mathrm{~g} / \mathrm{L}$ ), adjust $\mathrm{pH}$ to 7.5 , autoclave, fill to $1 \mathrm{~L}$ with $\mathrm{dH}_{2} \mathrm{O}$,

11. Glycine buffer (100 $\mathrm{nM}): 3.75 \mathrm{~g}$ of glycine (100 mM final concentration), $900 \mathrm{~mL}$ of $\mathrm{dH}_{2} \mathrm{O}$, adjust to $\mathrm{pH} 2$, fill to $1 \mathrm{~L}$ with $\mathrm{dH}_{2} \mathrm{O}$, filter at $0.22 \mu \mathrm{M}$.

12. Tris buffer $(1 \mathrm{M})$ : $12.114 \mathrm{~g}$ of Tris base (final concentration $1 \mathrm{M}$ ), $80 \mathrm{~mL}$ of $\mathrm{dH}_{2} \mathrm{O}$, adjust solution to $\mathrm{pH} 8.8$, add $\mathrm{dH}_{2} \mathrm{O}$ to final volume of $100 \mathrm{~mL}$.

13. $10 \%$ Sodium Deoxycholate solution: $1 \mathrm{~g}$ of sodium deoxycholate, $10 \mathrm{~mL}$ of $\mathrm{dH}_{2} \mathrm{O}$.

14. Ethanol.

15. PBS.

16. Benzonase.

17. POROS ${ }^{\mathrm{TM}}$ CaptureSelect ${ }^{\mathrm{TM}}$ AAVX Resin or pre-packed column.

18. Dialysis cassette (Side-A-Lyzer; ThermoFisher Scientific).

19. Amicon Ultra 15_100kDa MWCO.

20. $1.5 \mathrm{~mL}$ Eppendorf with $0.22 \mu \mathrm{m}$ filter. 
2.7 Titration of Lentiviral and AAV vectors

1. Blood and Tissue Kit (Qiagen).

2. StepOne Plus, QuantStudio 3 (ThermoScientific) or similar qPCR machine.

3. Primers and probe set for target sequences (Table 1), LTR [11] and $\beta$-actin are used for lentivirus and SV40 for AAV titration.

4. Standard for qPCR; plasmid used to produce the vector ( $\beta$-actin should be present in the construct). Prepare a serial dilution (1:10) between $1 \times 10^{9}$ copies $/ 5 \mu l$ down to $1 \times 10^{2}$ copies $/ 5 \mu l$. The range can be adjusted according to your particular vector.

5. Luna Universal Probe qPCR MasterMix (NEB).

6. 96-well PCR plate $0.1 \mathrm{~mL}$ format.

7. MicroAmp ${ }^{\circledR}$ Optical Adhesive Film (Applied Biosystems).

Table 1. Primers and probes used for lentivirus and AAV vector titration

\begin{tabular}{l|l}
\hline Primer & Sequence \\
\hline LTR - Forward & 5'-TGTGTGCCCGTCTGTTGTGT-3' \\
LTR - Reverse & 5'-GAGTCCTGCGTCGAGAGAGC-3' \\
LTR - Probe & 5'-(FAM)-CAGTGGCGCCCGAACAGGGA-(3BHQ_1)-3' \\
$\beta$-actin - Forward & 5'-GTAGCACAGCTTCTCCTTAAT-3' \\
$\beta$-actin - Reverse & 5'-GGACCTGACTGACTACCT-3' \\
$\beta$-actin - Probe & 5'-(FAM)-CGCGCTCGGTGAGGATCTTCAT-(3BHQ_1)-3' \\
SV40 - Forward & 5'-CACAACTAGAATGCAGTGAAA-3' \\
SV40 - Reverse & 5'-AACTTGTTTATTGCAGCTTAT-3' \\
SV40 - Probe & 5'-(FAM)-TGGTTACAAATAAAGCAATAGCATCAC-(3BHQ_1)-3' \\
\hline
\end{tabular}


2.8 in vivo bioluminescent imaging

1. Potassium luciferin, D-luciferin.

2. Dulbecco's phosphate-buffered saline (DPBS), no calcium and magnesium.

3. 33-gauge Hamilton needle.

4. $1 \mathrm{ml}$ syringe with needle $(16 \mathrm{~mm})$.

5. Imaging chamber box, $5 \mathrm{~cm} \times 5 \mathrm{~cm} \times 6 \mathrm{~cm}$.

6. Perspex box, as shown in Karda et al. [8].

7. IVIS imaging system (Perkin Elmer).

8. Oxygen.

9. Isoflurane.

10. Mice CD1 strain (Charles River Laboratories, UK).

\section{Methods}

3.1 Cloning lentiviral and AAV plasmids

Cloning of synthetic promoter and response elements in lentiviral plasmids has been previously described in greater detail by Delhove et al. [10].

1. Design serial transcription factor binding sequence (TFBS) with 4-10 interspaced binding sequences with 10 random nucleotides between each TFBS.

2. Synthesize TFBS sequence with flanking 5' BamHI and 3' EcoRI restriction sites. Use for direct cloning into pENTR.

3. BamHI/EcoRI digest the pENTR vector and gel extract backbone. 
4. Clone TFBS sequence into pENTR, transform into DH5 $\alpha$ competent cells, and select using kanamycin-laden agar plates $(50 \mu \mathrm{g} / \mathrm{ml})$.

5. Select individual clones, grow in kanamycin-laden LB broth $(50 \mu \mathrm{g} / \mathrm{ml})$ and isolate plasmid.

6. Perform a BamHI/EcoRI double digest to confirm presence of the TFBS insert in the pENTR plasmid.

7. Confirm sequence using the following pENTR primer. The primer binding site is $81 \mathrm{bp}$ upstream from the BamHI site (ACTGATAGTGACCTGTTCGTTGC).

8. Using the LR clonase kit, perform the LR reaction between the pENTR plasmid containing the response element or promoter of choice and pLNT-GW-JDG or AAV-GWJDG, by following the manufacturer's guidelines.

9. Transform $1 \mu \mathrm{l}$ of reaction mixture into Stbl 3 competent cells and grow overnight at $30^{\circ} \mathrm{C}$ on an ampicillin $(100 \mu \mathrm{g} / \mathrm{ml}) \mathrm{LB}-$ agar plate.

10. Select individual colonies and grow in shaking incubator $(200 \mathrm{rpm})$ overnight at $30^{\circ} \mathrm{C}$ in $5 \mathrm{ml}$ of LB broth containing ampicillin $(100 \mu \mathrm{g} / \mathrm{ml})$.

11. Screen colonies using an appropriate restriction enzyme digest to distinguish the clones form the original Gateway-containing parental plasmid and perform gel electrophoresis.

12. For pLNT-GW-JDG, it is a BamHI digest (10, 928 bp, 857 bp, 702 bp, 228 bp, 12 bp (not seen on gel)). The 857 and 702 bands are removed and exchanged for an approximately $300 \mathrm{bp}$ band when recombination has been successful. For AAV-GW-JDG it is dependent on the insert. 


\subsection{Lentivirus transfection}

Carry out all experiments in a cell culture hood.

1. Seed $2 \times 10^{7}$ HEK293T cells in T175 flasks and leave overnight until they are $90 \%$ confluent (see Note 1).

2. For each flask mix the following concentrations of plasmids in $6 \mathrm{ml}$ of Opti-MEM; $50 \mu \mathrm{g}$ of payload plasmid, containing luciferase transgene, $32.5 \mu \mathrm{g}$ of packaging plasmid and $17.5 \mu \mathrm{g}$ of envelop plasmid. In a separate falcon tube, mix $1 \mu \mathrm{l}$ of $10 \mathrm{mM}$ PEI in $6 \mathrm{ml}$ of Opti-MEM.

3. Mix the two plasmid DNA and PEI solutions together and leave to incubate for 20 minutes at room temperature.

4. Remove DMEM from cells and wash with DPBS.

5. Add $12 \mathrm{ml}$ of the PEI and plasmid DNA mix to each flask and incubate for 4 hours. After which remove media and replace with fresh $15 \mathrm{ml}$ of DMEM (supplemented with $10 \%$ FBS and $1 \%$ Pen/Strep).

6. After 48 hours remove supernatant and filter in $0.45 \mu \mathrm{m}$ PVDF membrane. Add supernatant to $50 \mathrm{ml}$ falcon tubes and spin for 20 hours at $4800 \mathrm{~g}$ at $4^{\circ} \mathrm{C}$.

7. Remove supernatant (see Note 2) and add $50 \mu$ of Opti-MEM per flask to tube, in order to re-suspend viral pellet. Leave on ice for 1 hour with gentle mixing every 20 minutes, careful not to introduce bubbles and then cryopreserve at $-80^{\circ} \mathrm{C}$. 


\subsection{Lentiviral titration}

The HT1080 cell line was used for this protocol, as they have been shown to have a stable karyotype [12].

1. Seed 100,000 cells into each well of a tissue cultured treated 6-well plate.

2. The following day add the virus; using concentrated vector in dilutions of: 1:2, 1:4, 1:8, 1:16 and 1:32.

3. 72 hours post transfection, passage cells. Repeat this once more.

4. Collect cells and extract DNA using Blood and Tissue kit (Qiagen), following manufacturer's protocol.

5. Determine concentration of DNA sample. Each sample should be diluted to $20 \mathrm{ng} / \mu \mathrm{l}$.

6. All samples are run in triplicates, along with standards.

7. Add the $15 \mu$ l master mix, shown in Table 2 .

8. Add $5 \mu \mathrm{l}$ for each sample and standard.

9. Run qPCR using the settings, shown in Table 3.

10. Obtain absolute copy number values from qPCR run, based on standard curves of known DNA copy number concentration for LTR and $\beta$-actin.

11. Vector titration calculated using formula [13] (see Note 3);

$$
\text { vector copy number }=\frac{\text { copy number LTR }}{\text { copy number } \beta \text { actin }} \times 2
$$

12. To obtain the functional titre, use the following equation (see Note 4);

$$
\text { Titre }(T U / m l)=\frac{\text { cells in day } 1 \times \text { vector copy number }}{\text { volume }(\mathrm{ml})}
$$


Table 2. Reaction mixture for lentivirus qPCR

\begin{tabular}{|l|l|l|l|}
\hline Reagent & Stock concentration & Final concentration & 1rx $(\mu \mathrm{l})$ \\
\hline $\begin{array}{l}\text { Luna qPCR } \\
\text { MasterMix }\end{array}$ & $2 \mathrm{x}$ & $1 \mathrm{x}$ & 10 \\
\hline Forward primer & $100 \mu \mathrm{M}$ & $450 \mathrm{nM}$ & 0.09 \\
\hline Reverse primer & $100 \mu \mathrm{M}$ & $450 \mathrm{nM}$ & 0.09 \\
\hline Probe & $100 \mu \mathrm{M}$ & $250 \mathrm{nM}$ & 0.05 \\
\hline $\mathrm{H}{ }_{2} \mathrm{O}$ & - & - & 4.77 \\
\hline Total & & & $15 \mu \mathrm{l}$ \\
\hline
\end{tabular}

Table 3. qPCR settings for Lentivirus titration

\begin{tabular}{|l|l|l|l|}
\hline Stage & Temperature & Time & Cycles \\
\hline Initial denaturation & $95^{\circ} \mathrm{C}$ & 10 minutes & 1 \\
\hline Denaturation & $95^{\circ} \mathrm{C}$ & 15 seconds & \multirow{2}{*}{$40-45$} \\
\hline Extension & $60^{\circ} \mathrm{C}$ & 45 seconds & \\
\hline
\end{tabular}

\subsection{AAV transfection}

Carry out all experiments in a cell culture hood.

1. Seed $2 \times 10^{7}$ HEK293T cells in $15 \mathrm{~cm}$ dish (using DMEM, 10\% FBS and 1\% Pen/Strep) and leave overnight until they are $90 \%$ confluent (see Note 1).

2. For each dish mix the following concentrations of plasmids in $1.6 \mathrm{ml}$ of Opti-MEM; 7.14 $\mu \mathrm{g}$ of payload plasmid, containing luciferase transgene, $7.14 \mu \mathrm{g}$ of AAV-Capsid plasmid 
and $21.4 \mu \mathrm{g}$ of Helper plasmid. In a separate falcon tube, mix $75 \mu \mathrm{l}$ of $0.1 \%$ PEI in $1.6 \mathrm{ml}$ of Opti-MEM.

3. Filter the DNA mixture though a $0.22 \mu \mathrm{m}$ membrane filter.

4. Mix the two plasmid DNA and PEI solutions together.

5. Leave to incubate for 20 minutes at room temperature to form DNA/PEI complexes.

6. Carefully add $3 \mathrm{ml}$ of the mixture to each dish in a drop-wise fashion.

7. Incubate overnight at $37^{\circ} \mathrm{C}, 5 \% \mathrm{CO}_{2}$.

8. Remove the media from the cells, replace with $15 \mathrm{ml} \mathrm{DMEM,} \%$ FBS and 1\% Pen/Strep.

9. Incubate for 48 hours at $37^{\circ} \mathrm{C}, 5 \% \mathrm{CO}_{2}$.

10. Scrape off cells from each plate and collect with the media into $50 \mathrm{ml}$ falcon tubes and centrifuge at $3100 \mathrm{~g}$ for 10 minutes. Store the supernatant at $4^{\circ} \mathrm{C}$.

11. Resuspend the cell pellet in TD Buffer, $1 \mathrm{~mL}$ per plate, and store at $-80^{\circ} \mathrm{C}$.

12. Cell pellet: 5 freeze-thaw cycles moving between a water bath at $37^{\circ} \mathrm{C}$ and dry ice. Then add $50 \mu \mathrm{l}$ of $10 \%$ sodium deoxycholate per $\mathrm{ml}$ of TD buffer and $0.2 \mu \mathrm{l}$ of Benzonase per $\mathrm{ml} \mathrm{TD}$ buffer. Incubate for $30 \mathrm{~min}$ at $37^{\circ} \mathrm{C}$ followed by centrifugation at $3100 \mathrm{~g}$ for $30 \mathrm{~min}$ at $4^{\circ} \mathrm{C}$. Using a syringe, filter the supernatant through a PES $0.45 \mu \mathrm{m}$ sterile filter, store the solution at $4^{\circ} \mathrm{C}$ for up to 24 hours. Discard the pellet.

13. Supernatant: add $1 \mu \mathrm{l}$ of Benzonase per $10 \mathrm{ml}$ of supernatant and $2 \mu \mathrm{l}$ of $100 \mathrm{mM}$ magnesium sulfate $\left(\mathrm{MgSO}_{4}\right)$ per $1 \mathrm{ml}$ of supernatant, incubate for $30 \mathrm{~min}$ at $37^{\circ} \mathrm{C}$ followed by centrifugation at $3100 \mathrm{~g}$ for $30 \mathrm{~min}$ at $4^{\circ} \mathrm{C}$. Filter the media through a $0.45 \mu \mathrm{m}$ PVDF stericup, store the solution at $4^{\circ} \mathrm{C}$ for up to 24 hours. Discard the pellet. 


\subsection{AAV purification by HPLC}

1. Clean the HPLC machine with $75 \mathrm{~mL}$ of $20 \%$ ethanol followed by $75 \mathrm{~mL}$ of PBS, make sure the $\mathrm{pH}$ and absorbance lines are stable and the values reach baseline (zero is the baseline reading).

2. Position the POROS column and wash with PBS.

3. Position FACS tubes in the system, add $30 \mu \mathrm{l}$ of $1 \mathrm{M}$ Tris solution to each.

4. Run the supernatant from the cell pellet through the system. The absorbance curve should increase significantly while the solution passes though the column, the $\mathrm{pH}$ curve should remain stable. Wash the system with PBS (approximately $75 \mathrm{~mL}$ ) until the reading reaches the set baseline; collect the waste in another sterile container and run it though the system following the same procedure.

5. Collect the bound vector by eluting into FACS tubes, $1 \mathrm{~mL}$ glycine solution. Neutralize the $\mathrm{pH}$ by adding $30 \mu \mathrm{l}$ of $1 \mathrm{M}$ Tris to each FACS tube. To identify the fraction containing the vector follow the absorbance curves, the $\mathrm{pH}$ should decrease, and absorbance should increase as the fraction is eluted (Fig. 2). The vector could be eluted in more than one fraction.

6. Transfer all the fractions into the dialysis cassette and leave to spin using a magnetic stirrer in $1 \mathrm{~L}$ of PBS overnight to restore $\mathrm{pH}$.

7. Wash the system with PBS and repeat the same procedure for the supernatant.

[Figure 2 near here] 


\subsection{AAV concentration}

1. Prime the Amicon Ultra 15_100kDa MWCO filter with $5 \mathrm{ml}$ of PBS, centrifuge at $4000 \mathrm{~g}$ for 5 minutes.

2. Add the unconcentrated vector from the cassette to the filter and centrifuge at $4000 \mathrm{~g}$ for 5 minutes.

3. Discard the flow-through and collect the remaining vector in the filter.

4. Add vector to $1.5 \mathrm{~mL}$ Eppendorf with 0.22 um filter, centrifuge at $12000 \mathrm{~g}$ for 3 minutes.

5. Remove the filter and aliquot and store at $4^{\circ} \mathrm{C}$ for short-term use or $-80^{\circ} \mathrm{C}$ for long-term storage.

\subsection{AAV titration}

Digest virus to release DNA:

1. In one PCR tube add: $5 \mu \mathrm{L}$ of the rAAV vector to be titrated, $5 \mu \mathrm{L}$ of DNAse digestion buffer, 10 units of DNAse I, make final volume to $50 \mu \mathrm{l}$ with $\mathrm{dH}_{2} \mathrm{O}$.

2. Incubate at $37^{\circ} \mathrm{C}$ for 30 minutes and inactivate for 10 minutes at $65^{\circ} \mathrm{C}$ (see Note 5 ).

3. Prepare 7 serial dilutions of the digested vector, usually 1:10.

4. Prepare qPCR Master Mix (for SV40) (Table 4).

5. Add the Master Mix to all the necessary wells, followed by triplicates of the standards and each dilution of the vector ( $5 \mu \mathrm{l}$ of each), for a total volume of $20 \mu \mathrm{l}$.

6. For SV40 primers, run the samples with the settings in Table 5.

7. Determine the number of copies obtained for each corresponding dilution from the qPCR machine. Ensure the quality control parameters for the run have been met (see Note 6). 
8. Use the following formula to calculate the vector titration (see Note 7);

$$
\text { Titre }(\mathrm{vc} / \mathrm{ml})=\frac{C}{5} \times 1000 \times D \times 10 \times 2
$$

Table 4. Master Mix for AAV qPCR titration

\begin{tabular}{|l|l|l|l|}
\hline Reagent & Stock concentration & Final concentration & 1rx $(\mu \mathbf{l})$ \\
\hline $\begin{array}{l}\text { Luna qPCR Master } \\
\text { Mix }\end{array}$ & $2 \mathrm{x}$ & $1 \mathrm{x}$ & 10 \\
\hline Forward primer & $100 \mu \mathrm{M}$ & $450 \mathrm{nM}$ & 0.09 \\
\hline Reverse primer & $100 \mu \mathrm{M}$ & $450 \mathrm{nM}$ & 0.09 \\
\hline Probe & $100 \mathrm{nM}$ & $250 \mathrm{nM}$ & 0.05 \\
\hline $\mathrm{H}_{2} \mathrm{O}$ & - & - & 4.77 \\
\hline Total & & & $15 \mu \mathrm{l}$ \\
\hline
\end{tabular}

Table 5. qPCR settings for AAV titration

\begin{tabular}{|l|l|l|l|}
\hline Stage & Temperature & Time & Cycles \\
\hline Initial denaturation & $95^{\circ} \mathrm{C}$ & 10 minutes & 1 \\
\hline Denaturation & $95^{\circ} \mathrm{C}$ & 15 seconds & \multirow{2}{*}{$40-45$} \\
\hline Extension & $60^{\circ} \mathrm{C}$ & 45 seconds & \\
\hline
\end{tabular}




\subsection{Animal procedures}

All procedures were performed under United Kingdom Home Office Project License 70/8030, approved by the ethical review committee and followed institutional guidelines as outlined by University College London. Outbred CD1 mice (see Note 8) were used and supplied by Charles River.

\subsubsection{Administration of vectors to neonatal mice}

1. New born mice (first day of development), briefly expose to hypothermic anaesthesia, by placing them on wet ice.

2. Inject $5 \mu \mathrm{l}$ of concentrated lentivirus or AAV (see Note 9) into cerebral lateral ventricles of one brain hemisphere (see Note 10) using 33 gauge Hamilton needle, by following coordinates shown by Kim et al. [14].

3. Place mice back in dam.

4. For intravenous injections, briefly expose hypothermic anaesthesia. Inject $20 \mu \mathrm{l}$ into superficial temporal vein [1], using 33 gauge Hamilton needle.

5. Place mice back in dam.

\subsubsection{Bioluminescent imaging}

1. Where appropriate (see Note 11), anesthetise mice with isoflurane and 100\% oxygen.

2. Administer $15 \mathrm{mg} / \mathrm{ml}$ of D-luciferin to mice via intraperitoneal injections (see Note 12).

3. Leave for 5 minutes (see Note 13). 
4. Mice which have received an intracranial injection of vector, should be placed in an imaging chamber with the following dimension; $5 \mathrm{~cm} \times 5 \mathrm{~cm} \times 6 \mathrm{~cm}$ (see Note 14). Mice which have received an intravenous injection, should be placed in Perspex box.

5. Place imaging chambers into IVIS machine and take images between 1 second and 5 minutes.

6. Return mice to their cages (see Note 15).

7. Measure luciferase expression by using Living Image Software (Perkin Elmer). Select region of interest (see Note 16) and measure photons per second per centimetre squared per steradian (photons/second $/ \mathrm{cm}^{2} / \mathrm{sr}$ ).

\section{$4 \quad$ Notes}

1. Make sure cells are healthy (mycoplasma negative) and have been passaged every second day for at least 3 passages prior to vector production.

2. Remove excess media by placing the falcon tube upside down on tissue paper sprayed with $70 \%$ IMS.

3. This calculates the vector copy number per cell in the sample; the 2-fold factor accounts for the two alleles of the $\beta$-actin gene.

4. Cell concentrations at the day of transfection are around 200,000. The average titre of all the dilutions from the same sample are considered in the final titre.

5. Optional, add 0.4 units of proteinase $\mathrm{K}$ [15], incubate for 1 hour at $50^{\circ} \mathrm{C}$ and inactivate for 20 minutes at $95^{\circ} \mathrm{C}$.

6. The qPCR reaction quality should be the following; efficiency between $90-110 \%, R^{2}>$ 0.98, replicates within $0.5 \mathrm{Ct}$ of each other, no template control above Ct35. 
7. Where $\mathrm{C}$ is the copies measured from the reaction. It is divided by 5 to account for the 5 $\mu \mathrm{l}$ used in the qPCR reaction. 1000 is the conversion factor from $\mu \mathrm{l}$ to $\mathrm{ml}, \mathrm{D}$ is the dilution factor (i.e. for a 1:2 dilution from the digested vector, this will be 2 ) and 10 is the initial dilution of the AAV vector in the digestion $(5 \mu \mathrm{l}$ in $50 \mu \mathrm{l}) .2$ account for the complementary strand not targeted by the primers.

8. Mice with white fur are best to use for bioluminescence. Mice with dark fur make detection of the photons difficult as the dark hair absorbs the luminescent signal more so than the white hair. Dark coloured mice are therefore routinely shaved in order to maximise luciferase expression.

9. Concentrated lentivirus that has a titre greater than $1 \times 10^{8} \mathrm{vg} / \mathrm{ml}$ and AAV greater than $1 \times 10^{12} \mathrm{vg} / \mathrm{ml}$

10. Keep the needle moist by placing it between a wet tissue paper. This reduces the friction between the needle and skin of mice and prevents the contents of the needle from drying out and blocking the tip.

11. Mice can be imaged consciously, without the use of anaesthesia.

12. Use a 33 gauge Hamilton needle to inject mice with D-luciferin, up to 10-12 days of age. After which use a $1 \mathrm{ml}$ syringe and 27 gauge needle. Also make sure that the bladder or other internal organs are not penetrated by the needle.

13. Leave for 5 minutes after luciferin administration as this allows the luciferin to enter into the bloodstream.

14. Once mice have passed the age of 15/16 days, they should be imaged while conscious in an imaging chamber of the following dimensions; $11 \mathrm{~cm} \times 7 \mathrm{~cm} \times 6 \mathrm{~cm}$.

15. If the mice have been imaged using anaesthesia, return mice to cage and wait until they have gained consciousness and are clearly mobile before leaving unattended. 
16. The surface area of the imaging chamber is taken as a region of interest. For example, the imaging chamber for intracranial injected mice is $5 \mathrm{~cm} \times 5 \mathrm{~cm}$.

\section{Acknowledgements}

JMKMD and SNW were funded by the ERC grant Somabio (260862), TRM and SNW were funded by the NC3Rs (NC/L001780/1). RK and SNW received funding from MRC grants MR/P026494/1 and MR/R015325/1, and from SPARKS grant 17UCL01. JAD is funded by CONICYT Becas Chile Doctoral Fellowship Program 72160294

\section{References}

[1] S. M. K. Buckley et al., "In vivo bioimaging with tissue-specific transcription factor activated luciferase reporters,"Sci. Rep., vol. 5, p. 11842, 2015.

[2] P. Ciana et al., "Engineering of a Mouse for the in Vivo Profiling of Estrogen Receptor Activity," Mol. Endocrinol., vol. 15, no. 7, pp. 1104-1113, 2001.

[3] N. Ward et al., "Codon optimisation of human factor VIII cDNAs leads to high level expression," Blood, vol. 117, no. 3, pp. 798-808, 2010.

[4] S. M. K. Buckley et al., "Luciferin detection after intranasal vector delivery is improved by intranasal rather than intraperitoneal luciferin administration.," Hum. Gene Ther., vol. 19, no. 10, pp. 1050-1056, 2008.

[5] J. C. Wu, G. Sundaresan, M. Iyer, and S. S. Gambhir, "Noninvasive optical imaging of firefly luciferase reporter gene expression in skeletal muscles of living mice," Mol. Ther., vol. 4, no. 4, pp. 297-306, 2001.

[6] Y. K. Ryu, S. Khan, S. C. Smith, and C. D. Mintz, "Isoflurane impairs the capacity of astrocytes to support neuronal development in a mouse dissociated coculture model.," J. Neurosurg. Anesthesiol., vol. 26, no. 4, pp. 363-8, 2014.

[7] K. D. Broad et al., "Isoflurane Exposure Induces Cell Death, Microglial Activation and Modifies the Expression of Genes Supporting Neurodevelopment and Cognitive Function in the Male Newborn Piglet Brain.," PLoS One, vol. 11, no. 11, p. e0166784, 2016. 
[8] R. Karda et al., "Continual conscious bioluminescent imaging in freely moving somatotransgenic mice," Sci. Rep., vol. 7, no. 1, p. 6374, 2017.

[9] R. Karda et al., "Generation of light-producing somatic-transgenic mice using adenoassociated virus vectors," bioRxiv, 2018.

[10] D. Gould, Mammalian Synthetic Promoters, vol. 1651. 2017.

[11] K. E. Yoder and R. Fishel, "Real-time quantitative PCR and fast QPCR have similar sensitivity and accuracy with HIV cDNA late reverse transcripts and 2-LTR circles," $J$. Virol. Methods, vol. 153, no. 2, pp. 253-256, 2008.

[12] T. R. Chen, R. J. Hay, and M. L. Macy, "Intercellular karyotypic similarity in neardiploid cell lines of human tumor origins," Cancer Genet. Cytogenet., vol. 10, no. 4, pp. 351-362, 1983.

[13] W. Barczak, W. Suchorska, B. Rubiś, and K. Kulcenty, "Universal Real-Time PCRBased Assay for Lentiviral Titration,” Mol. Biotechnol., vol. 57, no. 2, pp. 195-200, 2014.

[14] J. Y. Kim et al., "Viral transduction of the neonatal brain delivers controllable genetic mosaicism for visualising and manipulating neuronal circuits in vivo," Eur. J. Neurosci., vol. 37, no. 8, pp. 1203-1220, 2013.

[15] N. J. Werling, S. Satkunanathan, R. Thorpe, and Y. Zhao, "Systematic Comparison and Validation of Quantitative Real-Time PCR Methods for the Quantitation of Adeno-Associated Viral Products," Hum. Gene Ther. Methods, vol. 26, no. 3, pp. 8292, 2015.

\section{Figure Legends}

Figure 1. Schematic diagram of the constructs used in Gateway cloning. (A) The pENTR plasmid contains the desired response element or promoter. (B) Lentiviral construct contains the central polypurine tract (cPPT), gateway upstream of a 3x FLAG-tagged tag, codon optimised luciferase, linked to enhanced green fluorescent protein by a T2A sequence. Also contains a woodchuck hepatitis virus posttranscriptional regulatory element (WPRE). (C) 
From 5'ITR to 3'ITR the AAV construct contains the same sequence as the lentiviral plasmid, except for the cPPT element. Not drawn to scale.

Figure 2. AAV vector purification by HPLC. The absorbance (in milli-Absorbance Units, mAu) curve (blue) in the HPLC software will show the proteins passing through the system. After establishing a baseline (0), a significant increase in the signal marks the proteins from the cell pellet passing though the column (1). Once baseline is reached again, the vector is collected (2). The insert shows a magnification of peak 2, in which the $1 \mathrm{ml}$ fractions are collected into FACS tubes which contain AAV vector. The fractions which contain vector, show a peak in absorbance. In the figure it is fractions 4,5 and 6 . If waste is collected, it should show a similar increase in the absorbance (3), but the elution peak will be significantly less (4). The supernatant takes longer as the volume is much larger (5). The elution peak reaches similar levels as the one obtained in the cell pellet (6). 